\title{
Pengaruh Inokulasi Azotobacter terhadap Produksi dan Kandungan Kadmium Tajuk Selada yang Ditanam di Andisol Terkontaminasi Kadmium
}

\author{
Reginawanti Hindersah ${ }^{1}$, Asep Purnama Hidayat ${ }^{2}$ dan Mahfud Arifin ${ }^{1}$ \\ ${ }^{1}$ Fakultas Pertanian Universitas Padjadjaran \\ Jl. Raya Jatinangor Km.21 Bandung 40600 \\ ${ }^{2}$ Alumni Fakultas Pertanian Universitas Padjadjaran \\ Staf Departemen Pertanian RI \\ Korespondensi: reginawanti@yahoo.com
}

\begin{abstract}
Effect of Azotobacter inoculation on yield and cadmium content of lettuce grown on cadmium-contaminated Andisols

Intensive application of organic matter and phosphate inorganic fertilizer could enhance cadmium (Cd) content in soil. Production of Cd-accumulator leafy vegetable in such soil has a risk to increase $\mathrm{Cd}$ content in the edible part of vegetable. Inoculation of biofertilizer Azotobacter also could increase Cd uptake since Azotobacter produce exopolysachharides which mobilize $\mathrm{Cd}$. This field experiment has been done to verify effect of Azotobacter inoculation on the yield and $\mathrm{Cd}$ content in shoot of lettuce grown in Cd-Contaminated Andisols. The experimental design was randomized block design consisted of various concentration of Azotobacter inoculants. Results showed that inoculation of biofertilizer Azotobacter sp. LKM6 in a variety of concentration could enhance the fresh weight of lettuce shoots. However, with and without inoculation, Cd content in lettuce shoots was 2.25-2.50 $\mathrm{mg} \mathrm{kg}^{-1}$. This was higher than those recommended by FAO/WHO for leafy vegetable, $0.02 \mathrm{mg} \mathrm{kg}^{-1}$.
\end{abstract}

Key words: Andisols, Azotobacter, Cadmium, Exopolysachharides, Lettuce

\begin{abstract}
ABSTRAK
Aplikasi pupuk organik dan pupuk fosfat anorganik yang intensif dapat meningkatkan konsentrasi kadmium (Cd) tanah. Dengan demikian, budidaya sayuran akumulator Cd seperti selada meningkatkan resiko paparan Cd di tajuknya. Aplikasi pupuk hayati Azotobacter di lahan tersebut berpotensi meningkatkan serapan Cd karena Azotobacter memproduksi EPS yang memobilisasi Cd. Penelitian ini dilakukan untuk memastikan efek inokulasi Azotobacter terhadap produksi selada dan peningkatan Cd di tajuk selada yang ditanam di tanah Andisols terkontaminasi ringan oleh Cd. Penelitian lapangan dirancang dalam rancangan acak kelompok yang menguji beberapa konsentrasi inokulan. Hasil penelitian menunjukkan bahwa inokulasi pupuk hayati Azotobacter sp. LKM6 dengan konsentrasi 0,1-1,5 \% meningkatkan berat tajuk selada yang ditanam di lahan dengan $1,17 \mathrm{mg} \mathrm{kg}^{-1} \mathrm{Cd}$. Namun demikian, tanpa maupun dengan inokulasi, tajuk selada mengandung $\mathrm{Cd}$ sebesar 2,25-2,50 mg kg-1, lebih besar daripada ambang batas minimal Cd di sayuran daun menurut $\mathrm{FAO} / \mathrm{WHO}$ sebesar $0,02 \mathrm{mg} \mathrm{kg}^{1}$.

Kata kunci: Andisol, Azotobacter, Kadmium, Eksopolisakarida, Selada
\end{abstract}

\section{PENDAHULUAN}

Selada (Lactuca sativa L) adalah salah satu tanaman sayuran dengan tingkat konsumsi yang cukup tinggi di Pulau Jawa khususnya Jawa Barat. Produksi selada mensyaratkan suhu udara optimum $15-20 \quad{ }^{\circ} \mathrm{C}$ sehingga ditanam di pegunungan yang didominasi oleh jenis tanah Andisol yang subur. Pengalaman 
petani telah membuktikan bahwa tanpa penambahan bahan organik dan pemupukan intensif, produktivitas sayuran dataran tinggi termasuk selada akan menurun. Di tanah Andisol pemupukan organik berupa pupuk kandang menjadi keharusan. Pupuk TSP dan SP-36 dengan intensif diberikan untuk mengantisipasi fiksasi fosfat oleh liat amorf alofan di Andisol.

Salah satu efek negatif aplikasi bahan organik dan pupuk anorganik terutama TSP dan SP36 adalah masuknya kontaminan logam berat Cd dari bahan tersebut ke dalam tanah (Alloway, 1995b; Chien et al., 2003), Saat ini Cd total di tanah pertanian Lembang ada yang mencapai lebih dari 1 mg $\mathrm{kg}^{-1}$ padahal tanah Andisols alami di Lembang hanya mengandung $0,1 \mathrm{mg} \mathrm{kg}^{-1}$ (Sudirja \& Hindersah, 2007). Pada era pupuk hayati, mobilisasi Cd di dalam tanah dapat meningkat akibat aplikasi pupuk hayati yang memproduksi eksopolisakarida (EPS) seperti pemfiksasi nitrogen Azotobacter. EPS bakteri ini membentuk ikatan koordinasi dengan $\mathrm{Cd}$ (Chen et al., 1995) sehingga Cd tersedia dan lebih mudah diserap tanaman.

Beberapa hasil penelitian menunjukkan konsistensi peningkatan serapan $\mathrm{Cd}$ oleh tanaman akumulator Cd, selada, setelah aplikasi Azotobacter (Hindersah \& Kalay, 2006; Hindersah et al., 2007; 2007 a). Kemampuan EPS Azotobacter secara in vitro untuk mengadsorpsi $\mathrm{Cd}$ telah dibuktikan (Hindersah, 2008). Namun, pada penelitian tersebut, inokulan Azotobacter diproduksi pada media penginduksi produksi EPS. Dengan pertimbangan bahwa Azotobacter adalah pupuk hayati yang banyak digunakan dan pupuk organik cair sering mengandung bakteri pemfiksasi $\mathrm{N}_{2}$ ini, maka keamanan penggunaannya perlu diperhatikan. Penggunaan inokulan Azotobacter yang diproduksi pada media yang tidak terlalu menginduksi produksi EPS seperti media bebas $\mathrm{N}$, adalah salah satu alternatif menekan efek negatif Azotobacter. Penelitian ini bertujuan untuk memastikan efek inokulasi Azotobacter terhadap produksi selada dan peningkatan $\mathrm{Cd}$ di tajuk selada yang ditanam di tanah terkontaminasi ringan oleh $\mathrm{Cd}$.

\section{BAHAN DAN METODE}

Penelitian dilaksanakan di lahan Balai Besar Pelatihan Pertanian Lembang, ( \pm 1000 meter dpl) pada bulan Juli sampai dengan bulan Agustus tahun 2007. Tanah di lahan penelitian adalah Andisol (Lempung, pH 4,9, C organik $5.72 \%$, $\mathrm{N}$ total 0,22,
$\mathrm{C} / \mathrm{N} 26, \mathrm{P}$ total $45,0 \mathrm{mg} \mathrm{kg}^{-1}$, total $16 \% \mathrm{mg} 100$ $\mathrm{kg}^{-1}$, KTK 28, $35 \mathrm{cmol} \mathrm{kg}^{-1}$, Cd 1,17 $\mathrm{mg} \mathrm{kg}^{-1}$ ).

Azotobacter sp. isolat LKM 6 diperoleh dari Laboratorium Biologi dan Bioteknologi Tanah Fakultas Pertanian Unpad yang diisolasi dari rizosfir tanaman kubis merah di tanah Andisols Lembang. Bakteri ini memfiksasi $\mathrm{N}_{2}$ pada media Ashby bebas $\mathrm{N}$ dan menghasilkan EPS pada media Vermani. Inokulan bakteri dibuat pada media Ashby bebas $\mathrm{N}$ untuk menekan produksi EPS.

Percobaan lapangan ini menguji empat konsentrasi inokulan Azotobacter sp. isolat LKM6 dengan kepekatan $3.4 \times 10^{9}$ cfu $\mathrm{mL}^{-1}$ (inokulan cair:air, v:v) yaitu 0,1\%, 0,5 \%, 1,0 \% dan 1,5\%. Perlakuan kontrol tidak mendapatkan inokulan. Rancangan percobaan adalah Rancangan Acak Lengkap dengan dengan lima ulangan. Petak percobaan berukuran $2 \mathrm{~m}$ x $3 \mathrm{~m}$ dengan jarak antar petak $50 \mathrm{~cm}$. Bersamaan dengan pengolahan tanah, setiap petak diberi $12 \mathrm{~kg}\left(20 \mathrm{t} \mathrm{ha}^{-1}\right)$ pupuk kotoran kuda (pH 7,4, C organik 26,75 \%, N organik 0,71\%, $\mathrm{P}_{2} \mathrm{O}_{5}$ 1,54 \%, $\mathrm{K}_{2} \mathrm{O} 0,42 \%$, Cd 1,6 mg kg-1, kadar air $16,24 \%)$. Petak yang telah diolah kemudian ditutup memakai mulsa plastik yang selanjutnya diberi lubang berdiameter $15 \mathrm{~cm}$ pada jarak tanam $30 \mathrm{~cm} \times$ $30 \mathrm{~cm}$.

Benih selada daun (Leaf lettuce) varietas Green Orient dibibitkan di rak pembibitan plastik dengan media pupuk kotoran kuda dan tanah (1:1; $\mathrm{v}: \mathrm{v})$. Satu batang bibit selada daun (Leaf lettuce) varietas Green Orient berumur 21 hari ditanam di setiap lubang tanam. Tanaman diberi pupuk NPK Phonska (15-15-15) dengan dosis $400 \mathrm{~kg} \mathrm{ha}^{-1}$. Pada saat tanam, diberikan $1 / 3$ bagian NPK dan tiga minggu setelah tanam diberikan $2 / 3$ bagian lainnya. Inokulasi Azotobacter dilakukan tiga hari setelah tanam saat tanaman sudah tumbuh baik. Selanjutnya inokulan diberikan kembali seminggu kemudian. Setiap tanaman diberi $50 \mathrm{ml}$ inokulan Azotobacter untuk setiap aplikasi dengan konsentrasi inokulan sesuai perlakuan. Tanaman kontrol disiram dengan air dengan volume yang sama dengan inokulan. Tanaman disiram satu sampai dua kali sehari tergantung keadaan cuaca, dan dipelihara sampai 36 hari.

Saat panen dilakukan pengamatan terhadap konsentrasi $\mathrm{Cd}$ tersedia di sekitar perakaran, berat crop selada, dan konsentrasi Cd di tajuk selada. Sampel tanah dan tanaman berjumlah lima buah dari setiap petak percobaan dan diambil dengan cara acak tanpa mengikutsertakan tanaman di sisi petak. Konsentrasi Cd tanah dan tanaman ditentukan 
dengan Atomic Adsorption Spectrometry setelah destruksi dengan asam nitrat dan asam klorida (Sulaeman et al., 2005).

\section{HASIL DAN PEMBAHASAN}

\section{Berat Basah Tajuk Selada}

Inokulasi pupuk hayati Azotobacter meningkatkan berat tajuk selada (Tabel 1). Aplikasi 0,1\% inokulan sebanyak $50 \mathrm{~mL}$ bahkan dapat meningkatkan berat basah tajuk sebesar 20,4 \%. Meskipun peningkatan ini tidak signifikan secara statistik, tetapi pada jarak tanam 30 x $30 \mathrm{~cm}$ peningkatan hasil dalam hamparan kecil $100 \mathrm{~m}^{2}$ (populasi sekitar 1.000 tanaman) sudah meningkatkan hasil sekitar $11,74 \mathrm{~kg}$. Peningkatan ini secara ekonomis cukup berarti.

Peningkatan tertinggi dicapai pada apilikasi inokulan dengan konsentrasi 0,5 dan $1 \%$, selanjutnya terjadi penurunan berat basah ketika inokulan diberikan pada konsentrasi lebih tinggi yaitu 1,5\%. Berat basah tajuk mencapai 68,2 \% dan $63,1 \%$ lebih tinggi daripada kontrol untuk perlakuan 0,5 dan $1 \%$. Meskipun menurun, aplikasi inokulan dengan konsentrasi 1,5\% masih meningkatkan hasil 44,4\%.

Tabel 1. Pengaruh Azotobacter sp. isolat LKM6 terhadap berat basah tajuk selada

\begin{tabular}{lc}
\hline \multicolumn{1}{c}{ Konsentrasi inokulan } & $\begin{array}{r}\text { Rata-rata berat basah } \\
\left(\mathrm{g} \mathrm{tanaman}^{-1}\right)\end{array}$ \\
\hline $\begin{array}{l}\text { Kontrol (tanpa inokulan } \\
\text { Azotobacter })\end{array}$ & $57,52 \mathrm{a}$ \\
$\begin{array}{l}\text { Dengan Azotobacter } \\
\text { konsentrasi 0,1 \% } \\
\text { Dengan Azotobacter } \\
\text { konsentrasi 0,5\% }\end{array}$ & $69,26 \mathrm{ab}$ \\
$\begin{array}{l}\text { Dengan Azotobacter } \\
\text { konsentrasi 1 \% }\end{array}$ & $96,79 \mathrm{~cd}$ \\
$\begin{array}{l}\text { Dengan Azotobacter } \\
\text { konsentrasi 1,5\% }\end{array}$ & $83,82 \mathrm{~cd}$ \\
\hline
\end{tabular}

Keterangan: Nilai rata-rata yang diikuti dengan huruf yang sama tidak nyata menurut Uji Jarak Berganda Duncan pada taraf $5 \%$.

Inokulan yang digunakan, sebelum pengenceran, mengandung $3.4 \times 10^{9} \mathrm{cfu} \mathrm{mL}^{-1}$. Kepadatan ini termasuk tinggi sehingga pengenceran $0,1 \%$ berarti menurunkan populasi bakteri menjadi $3,4 \times 10^{6} \mathrm{cfu}$ $\mathrm{mL}^{-1}$. Dengan aplikasi dua kali $50 \mathrm{ml}$, maka Azotobacter yang ditambahkan pada setiap tanaman mencapai $3.4 \times 10^{7}$ cfu $\mathrm{mL}^{-1}$. Populasi Azotobacter di rizosfir tanaman umumnya hanya mencapai $10^{3}-10^{4} \mathrm{cfu} \mathrm{mL}^{-1}$, maka penambahan $3,4 \times$ $10^{7} \mathrm{cfu} \mathrm{mL}^{-1}$ meningkatkan populasinya selama pertumbuhan selada dalam jangka waktu 36 hari dan selanjutnya meningkatkan berat basah tajuk selada. Penurunan hasil pada perlakuan 1,5\% dapat disebabkan interaksi negatif dengan mikroba lain di rizosfir atau perakaran tanaman.

Pada penelitian ini, inokulan diproduksi pada media Ashby bebas $\mathrm{N}$ yang tidak terlalu menginduksi produksi EPS tetapi di dalam inokulan tetap didapatkan EPS sebesar $0,8 \mathrm{~g} \mathrm{~L}^{-1}$. Dua faktor utama peran Azotobacter sebagai pupuk hayati yaitu fiksasi nitrogen dan produksi fitohormon memerlukan kondisi bebas N (Subba Rao, 1982; Taller \& Wong, 1982). Peningkatan hasil selada ini dapat disebabkan oleh kapasitas di atas. Fiksasi gas dinitrogen dan produksi fitohormon telah dipastikan menginduksi pertumbuhan karena ketersediaan $\mathrm{N}$ meningkat dan fitohormon menginduksi pertumbuhan akar (Hindersah \& Simarmata, 2004). Dilihat dari produksi EPS oleh Azotobacter, peningkatan hasil dapat disebabkan oleh: 1) peningkatan porositas di sekitar rizosfir dan dan zone perakaran akibat adanya EPS, 2) peningkatan serapan unsur hara mikro dan trace element akibat kompleksasi oleh EPS yang mobil.

Alami et al. (2000) telah menjelaskan efek EPS yang diproduksi bakteri Rhizobium terhadap perbaikan agregasi dan porositas tanah setelah inokulasi. Agregasi tanah ini menyebabkan unsur hara nitrogen terserap lebih optimal. Penelitian Hindersah et al. (2006) pada pot dengan tanah Inceptisols memperlihatkan bahwa Azotobacter dapat meningkatan berat basah tajuk sebesar $10 \%$. Aplikasi di lapangan ternyata lebih meningkatkan hasil, karena percobaan pot tersebut dilakukan di ketinggian $730 \mathrm{~m} \mathrm{dpl}$ yang kurang cocok untuk pertumbuhan optimal selada.

Keberadaan EPS telah diketahui dapat berperan dalam mengkhelat unsur hara mikro dan trace element dan meningkatkan mobilisasinya di dalam tanah (Chen et al., 1995). Eksopolisakarida Azotobacter terbukti dapat mengadsorpsi Fe, Zn dan Cu (Emtiazi et al., 2004), dan mengadsorpsi Cd tanah, memobilisasi $\mathrm{Cd}$ tanah serta meningkatkan serapan Cd selada (Hindersah, 2008). Meskipun efek EPS terhadap peningkatan mobilisasi dan serapan unsur hara mikro maupun trace element esensial belum banyak dipelajari, mekanisme kompleksasi 
EPS-Cd di atas diduga dapat terjadi untuk unsur hara mikro esensial tersebut.

\section{Cd Tersedia Tanah}

Konsentrasi inokulan Azotobacter tidak berpengaruh terhadap Cd tersedia tanah (Tabel 2). Azotobactersp. LKM6 dapat memproduksi EPS dalam jumlah yang signifikan (Hindersah et al., 2006) dan menurut Chen et al. (1995), EPS berperan sebagai ligan organik yang memobilisasi logam berat. Kedua fakta tersebut dapat menyebabkan ketersediaan logam berat di dalam tanah meningkat.

Hasil penelitian yang terlihat pada Tabel 2 jelas bertolakbelakang dengan penelitian pot yang memperlihatkan peningkatan ketersediaan Cd tanah setelah aplikasi Azotobacter sp isolat LKM6 pada tanah Andisol dikontaminasi $10 \mathrm{mg} \mathrm{kg}{ }^{-1} \mathrm{Cd}$ (Hindersah et al., 2007a). Pada penelitian tersebut, inokulan diproduksi pada media Vermani yang menginduksi optimasi produksi EPS (Vermani et al., 1997). Selain itu, pada penelitian pot, Cd tanah terakumulasi di zone perakaran sehingga perubahan kelarutan Cd oleh EPS'Azotobacter menjadi lebih intensif. Data pada Tabel 2 menunjukkan bahwa inokulan cair Azotobacter yang diproduksi di dalam media Ashby dan diaplikasikan pada tanah terkontaminasi $\mathrm{Cd}$ ringan $\left(1,17 \mathrm{mg} \mathrm{kg}^{-1}\right)$ tidak berpotensi meningkatkan ketersediaan $\mathrm{Cd}$ tanah.

Tabel 2. Pengaruh Azotobacter sp. isolat LKM 6 terhadap Cd tersedia tanah

\begin{tabular}{lc}
\hline \multicolumn{1}{c}{ Konsentrasi inokulan } & $\begin{array}{c}\text { Cd tersedia tanah } \\
\left(\mathrm{mg} \mathrm{kg}^{-1}\right)\end{array}$ \\
\hline $\begin{array}{l}\text { Kontrol (tanpa inokulan } \\
\text { Azotobacter })\end{array}$ & 0,015 \\
$\begin{array}{l}\text { Dengan Azotobacter } \\
\text { konsentrasi 0,1 \% }\end{array}$ & 0,014 \\
$\begin{array}{l}\text { Dengan Azotobacter } \\
\text { konsentrasi 0,5 \% }\end{array}$ & 0,010 \\
$\begin{array}{l}\text { Dengan Azotobacter } \\
\text { konsentrasi 1 \% }\end{array}$ & 0,014 \\
$\begin{array}{l}\text { Dengan Azotobacter } \\
\text { konsentrasi 1,5 \% }\end{array}$ & 0,010 \\
\hline
\end{tabular}

\section{Cd Tajuk Tanaman}

Tidak adanya peningkatan ketersediaan Cd tanah menyebabkan setiap perlakukan tidak menyebabkan perbedaan jumlah $\mathrm{Cd}$ yang diserap oleh tanaman. Tabel 3 memperlihatkan bahwa konsentrasi Cd di tajuk tanaman berkisar antara 2,25-2,50 $\mathrm{mg} \mathrm{kg}^{-1}$.
Tabel 3. Pengaruh Azotobacter sp. isolat LKM 6 terhadap Cd tajuk Selada

\begin{tabular}{lc}
\hline \multicolumn{1}{c}{ Konsentrasi inokulan } & $\begin{array}{c}\text { Cd tajuk } \\
\left(\mathrm{mg} \mathrm{kg}^{-1}\right)\end{array}$ \\
\hline $\begin{array}{l}\text { Kontrol (tanpa inokulan } \\
\text { Azotobacter) }\end{array}$ & 2,25 \\
$\begin{array}{l}\text { Dengan Azotobacter } \\
\text { konsentrasi 0,1 \% }\end{array}$ & 2,31 \\
$\begin{array}{l}\text { Dengan Azotobacter } \\
\text { konsentrasi 0,5 \% }\end{array}$ & 2,31 \\
$\begin{array}{l}\text { Dengan Azotobacter } \\
\text { konsentrasi 1 \% }\end{array}$ & 2,50 \\
$\begin{array}{l}\text { Dengan Azotobacter } \\
\text { konsentrasi 1,5\% }\end{array}$ & 2,30 \\
\hline
\end{tabular}

Selada adalah tanaman akumulator Cd (Maier et al., 2003) yang mengakumulasi sebagian besar Cd di bagian tajuk (Alloway 1995a). Pada tanah yang dikontaminasi dengan $10 \mathrm{mg} \mathrm{kg}^{-1} \mathrm{CdCl}_{2}$, selada di dalam pot dapat mengakumualasi sampai 5,85 $\mathrm{mg} \mathrm{kg}^{-1} \mathrm{Cd}$ tanpa memperlihatkan gejala keracunan (Hindersah et al., 2007a). Nilai ambang batas Cd dalam tanaman yang dapat ditoleransi fungsi fisiologi tanaman adalah antara 5 - $10 \mathrm{mg} \mathrm{kg}^{-1}$ (Mengel \& Kirkby, 1987). Ambang batas Cd di sayuran daun untuk konsumsi yang direkomendasikan oleh Codex Alimentarious Commission FAO/WHO adalah $0,02 \mathrm{mg} \mathrm{kg}^{-1}$ (Ittana, 2002). Namun perlu diperhatikan bahwa asupan maksimum Cd bagi manusia adalah $200 \mathrm{mg} \mathrm{kg}^{-1}$ berat badan per hari (Alloway, 1995b) sehingga asupan Cd dari selada pada diet sehari-hari terhadap resiko keracunan Cd tidak signifikan. Namun demikian, kadar Cd di dalam selada ini dan juga di tanaman sayuran akumulator Cd seperti Brassicaceae perlu dicermati. Perhatian terhadap peningkatan serapan Cd di sayuran akumulator dapat menurunkan keamanan pangan.

\section{SIMPULAN DAN SARAN}

Inokulasi pupuk hayati Azotobacter sp. LKM6 dengan konsentrasi 0,1-1,5\% meningkatkan berat tajuk selada yang ditanam di lahan dengan 1,17 mg $\mathrm{kg}^{1} \mathrm{Cd}$. Namun demikian, tanpa maupun dengan inokulasi, tajuk selada mengandung 2,25-2,50 mg $\mathrm{kg}^{-1} \mathrm{Cd}$ yang lebih besar daripada ambang batas minimal $\mathrm{Cd}$ di sayuran daun menurut FAO/WHO sebesar $0,02 \mathrm{mg} \mathrm{kg}^{1}$. 


\section{UCAPAN TERIMAKASIH}

Kami berterimakasih kepada Kepala Balai Besar Pelatihan Pertanian (BBPP) Kayu Ambon Lambang dan Kepala Inkubator Agribisnis BBPP atas izinnya menggunakan lahan di BBPP.

\section{DAFTAR PUSTAKA}

Alami, Y, W Achouak, C Moral and T. Heulin, 2000. Rhizosphere soil aggregation and plant growth promotion of sunflowers by an exopolysaccharide-producing Rhizobium sp. strain isolated from sunflower roots. Appl. Environ. Microbiol. 66: 3393-3398.

Alloway, B.J. 1995a. The Origin of heavy metals in soils. Pp 38-57 in Heavy Metals in Soils. BJ Alloway (Ed). Blackie Academic and Professional, Glasgow.

Alloway, B.J. 1995b. Cadmium. Pp 122 - 151 in Heavy Metals in Soils. BJ Alloway (Ed). Blackie Academic and Professional, Glasgow.

Chen, J-H, DR Czajka, LW Lion, ML Shuler and WC Ghiorse. 1995. Trace metal mobilization in soil by bacterial polymers. Environ. Health Perspect. 103: 53-58.

Chien, SH, G Carmona, LL Prochnow and ER Austin. 2003. Cadmium avalability from granulated and bulk-blended phosphatepotassium fertilizers. J. Environ. Qual. 32: 1911-1914.

Emtiazi, G, Z.Ethemadifar and MH Habibi. 2004. Production of extracellular polymer in Azotobacter and biosorption of metal by exopolymer. Afr. J. Biotech. 3:330-333.

Hindersah, R dan T. Simarmata. 2004. Kontribusi rizobakteri Azotobacter dalam meningkatkan kesehatan tanah melalui fiksasi $\mathrm{N}_{2}$ dan produksi fitohormon di rizosfir. Jurnal Natur Indonesia. 6:127-133

Hindersah, R, dan AM Kalay. 2006. Akumulasi timah hitam dan kadmium pada tajuk selada setelah aplikasi Azotobacter dan lumpur IPAL. J.Budidaya Pertanian 2: 1-5

Hindersah, R, DH Arief, S Soemitro and L Gunarto. 2006. exopolysaccharide extraction from rhizobacteria Azotobacter sp. Proc. International Seminar IMTGT. Medan, 22-23 Juni 2006. Pp 50-55.

Hindersah, R, N Komaruddin and D Amelia. 2006. Cadmium accumulation on lettuce (Lactuca sativa L.) leaves following Azotobacter inoculation. J. Budidaya Pertanian 2: 86-91.

Hindersah, R, R Sudirja dan MR Setiawati. 2007. Akumulasi kadmium pada tajuk tanaman selada dan pakcoy setelah inokulasi Azotobacter sp. Ckl-5. Makalah dipresentasikan pada Seminar Kebudayaan Indonesia Malaysia. Kuala Lumpur 29-31 Mei 2007.

Hindersah, R, DH Arief, S Soemitro dan L Gunarto. 2007 a. Pengaruh inokulasi Azotobacter sp. LKM6 yang memproduksi eksopolisakarida dan aplikasi kadmium klorida terhadap kadmium di tanah dan tajuk selada Prosiding Kongres Himpunan Ilmu Tanah Indonesia, Jogja 5-7 Desember 2007. Hal 1140-1146.

Hindersah, R. 2008. Transportasi Kadmium dari Tanah ke Pupus Tanaman Selada (Lactuca Sativa L.) oleh Eksopolisakarida Azotobacter sp. Disertasi. Program Pascasarjana Universitas Padjadjaran, Bandung.

Itanna, F. 2002. Metals in leafy vegetables grown in Addis Ababa and toxicological implication. Ethiop. J. Health Dev. 16: 295-302.

Maier, EA, RD Matthews, JA McDowell, RR. Walden and BA. Ahnes. 2003. Environmental cadmium levels increase phytochelatin and glutathion in lettuce grown in a chelator-buffered nutrient solution. J. Environ. Qual. 32: 1356-1364.

Mengel, K and EA Kirkby. 1987. Principles of Plant Nutrition. International Potash Institute. Bern.

Sudirja, R dan R. Hindersah, 2007. Konsentrasi kadmium di lahan pertanian tanaman sayuran di Lembang Bandung. J. Peng. Will. 3: 6-10.

Subba-Rao. 1982. Biofertilizers in Agriculture. Oxford dan IBH Publ.Co. New Delhi.

Taller, BJ and TY Wong. 1989. Cytokinins in Azotobacter vinelandii Culture Medium. Appl. Environ. Microbiol. 55: 266-267.

Vargas-Garcia, MC, MJ Lopez, MA Elorrieta, F Suarez and J. Moreno. 2003. Properties of polysaccharides produced by Azotobacter vinelandii cultured on 4-hydroxybenzoic acid. J. Appl. Microbiol. 94: 389-395.

Vermani, MV, SM Kelkar and MY Kamat. 1997. Studies in polysaccharide production and growth of Azotobacter vinelandii MTCC 2459, a plant rhizosphere isolate. Lett. Appl. Microbiol. 24: 379-383. 
